\title{
ANALISIS KELAYAKAN FINANSIAL PEMBANGUNAN JALAN TOL BENOA-BANDARA-NUSA DUA
}

\author{
A.A. Astri Dewi ${ }^{1}$, P Alit Suthanaya ${ }^{2}$ dan D. M. Priyantha Wedagama ${ }^{2}$
}

\begin{abstract}
Abstrak: Ruas jalan By Pass Ngurah Rai merupakan satu-satunya jalan arteri primer yang menghubungkan arus lalu lintas orang dan barang dari Bandara Ngurah Rai menuju Nusa Dua. Kondisi volume jam puncaknya sudah melebihi kapasitas jalan tersebut. Untuk mengatasi permasalahan di atas, direncanakan membangun jalan Tol Benoa-Bandara-Nusa Dua. Tujuan dari penelitian ini adalah untuk menganalisis kinerja jalan eksisting tanpa dan dengan adanya jalan tol, tarif yang diberlakukan bagi pengguna jasa serta menganalisis kelayakan finansial terhadap proyek tersebut.

Analisis dilakukan terhadap beberapa tahap, diantaranya adalah tahap-1 dengan mengasumsikan faktor pertumbuhan lalulintas sebesar $\mathrm{i}=9,96 \% /$ tahun, suku bunga bank $16 \% /$ tahun, inflasi diperhitungkan 8,506\%/tahun dan tarif tol menggunakan tarif yang telah ditetapkan oleh Jasa Marga. Semua biaya termasuk biaya pembebasan lahan dan biaya konstruksi di tanggung oleh investor. Untuk tahap-1, mendapatkan hasil berupa nilai NPV Rp 1.586.137.984.347,-, BCR: 0,4754 dan IRR 3, 8676\%. Hasil analisis finansialnya mengindikasikan bahwa pembangunan jalan tol BenoaBandara-Nusa Dua tidak layak secara finansial. Agar proyek ini menjadi layak secara finansial, maka dikembangkanlah tahap-2, dengan tingkat pertumbuhan kendaraan $\mathrm{i}=14,7 \% /$ tahun.
\end{abstract}

Kata kunci : Jalan Tol, Kinerja, Tarif, Kelayakan Finansial

\section{FINANCIAL FEASIBILITY ANALYSIS OF BENOA-BANDARA-NUSA DUA TOLL ROAD DEVELOPMENT}

\begin{abstract}
By Pass Ngurah Rai is the only primary arterial road linking the traffic flow of people and goods from Ngurah Rai Airport to Nusa Dua. Peak hour traffic flow condition has exceeded the capacity of the road. To solve the above problems, it is planned to build toll roads Benoa-BandaraNusa Dua. The objectives of this study were to analyze the performance of existing roads with and without the toll road, the rates applicable to service users and to analyze the financial feasibility of the investment of the project.
\end{abstract}

Analysis was performed for several scenarios, including the scenario-1, assuming traffic growth factor of $i=9.96 \%$ / year, the interest rate $16 \%$ / year, inflation accounted for $8.506 \%$ / year and the toll rates using rates set by the Jasa Marga. All of the cost including land acquisition and construction costs were provided by investors. It was found that for the scenario-1, the NPV is Rp 1,586,137,984,347, -, BCR: 0.4754 and IRR 3, 8676\%. The results of the financial analysis indicated that investment of the toll roads Benoa-Bandara-Nusa Dua is not financially feasible. In order for this project to be financially feasible, the growth rate of vehicles should be at least $i=14.7 \%$ / year.

Keywords: Toll Roads, Performance, Rates, Financial Feasibility

\footnotetext{
${ }^{1}$ Mahasiswa Program Studi Magister Teknik Sipil, Program Pascasarjana Universitas Udayana.

${ }^{2}$ Staf Pengajar Program Studi Magister Teknik Sipil, Program Pascasarjana Universitas Udayana
} 


\section{PENDAHULUAN}

\section{Latar Belakang}

Transportasi merupakan bagian mendasar dari kehidupan seseorang yang secara umum melayani proses perpindahan orang atau barang dari suatu tempat ke tempat lain. Sasaran transportasi jalan berguna untuk menciptakan penyelenggaraan transportasi yang efektif dan efisien.

Perkembangan ekonomi yang menggembirakan utamanya di Bali Selatan, diimbangi dengan pertumbuhan jumlah penduduk menyebabkan berbagai permasalahan muncul, salah satu diantaranya adalah permasalahan transportasi. Beberapa penyebab lain yang menimbulkan masalah transportasi seperti yang terjadi pada Jalan By Pass Ngurai Rai adalah jalan ini merupakan satu-satunya jalan arteri primer yang menghubungkan arus lalu lintas orang dan barang dari / menuju Kuta, Jimbaran dan Nusa Dua. Kondisi lalu lintasnya sudah bisa dikatakan buruk dengan Volume Jam Puncak melebihi kapasitas jalan, sehingga memerlukan waktu lebih lama untuk melintasinya. Untuk mengatasi permasalahan di atas, direncanakan membangun ruas jalan alternative menuju ke Jimbaran dan Nusa Dua. Bila rencana tersebut terwujud, dapat diharapkan pendistribusian orang dan barang dari / ke Jimbaran dan Nusa Dua lebih lancar dan sekaligus dapat mengurangi beban lalulintas.

Untuk membangun jalan baru diperlukan biaya yang besar sementara keuangan pemerintah tidak cukup dimana pemerintah harus pula mempertimbangkan sektor lainnya demi pemerataan pembangunan. Bila mengharapkan peran swasta (investor), maka secara finansial investor harus mendapatkan keuntungan, yang artinya, pembangunan dan pengelolaannya diserahkan kepada pihak swasta (investor) dan oleh karenanya para pengguna jalan yang akan melewati rute tersebut dikenakan biaya/Tol (Tax On Location).

Terkait dengan kemungkinan pemerintah memberikan kesempatan kepada pihak swasta untuk membangun dan mengelola jalan tersebut di atas perlu dilakukan suatu kajian kelayakan terlebih dahulu. Hasil dari kajian kelayakan ini diharapkan menjadi dasar pertimbangan terhadap kebijakan yang akan dilaksanakan oleh pemerintah terkait dengan rencana pembangunan jalan tol tersebut. Pada penelitian ini dikaji kelayakan pembangunan jalan Tol Benoa-Bandara-Nusa Dua tersebut di atas berdasarkan trase terpilih dan kelayakan pembangunannya ditinjau dari segi finansial.

\section{Tujuan Penelitian}

Tujuan dari penelitian ini adalah: Untuk menganalisis kinerja jalan eksisting tanpa dan dengan adanya jalan tol Benoa-Bandara-Nusa Dua, menganalisis besar tarif tol yang dapat diberlakukan agar dapat mengimbangi biaya yang diperlukan, dan untuk menganalisis kelayakan finansial investasi pembangunan jalan tol sesuai manfaat yang diperoleh dan biaya yang diperlukan berdasarkan kriteria investasi

\section{TINJAUAN PUSTAKA}

\section{Arus dan Komposisi Lalu Lintas}

Lalu lintas harian rata-rata (LHR) adalah jumlah kendaraan yang melintasi suatu titik pengamatan pada suatu ruas jalan dalam satu hari (Dep. PU, 1997). Untuk menghitung LHRT haruslah tersedia data jumlah kendaraan yang terus menerus selama satu tahun penuh. Mengingat biaya yang diperlukan dan membandingkan ketelitian yang dicapai serta tidak semua tempat di Indonesia mempunyai volume lalu lintas selama satu tahun penuh, maka untuk kondisi tersebut dapat digunakan lalu lintas harian rata-rata (LHR). LHR atau LHRT untuk perencanaan jalan baru diperoleh dari analisa data yang diperoleh berdasarkan survey volume lalu-lintas (traffic counting) dan survei asal tujuan (O-D) di jalan tersebut atau jalan sekitarnya untuk pembangunan jalan baru. Salah satu metode untuk memprediksi arus lalu lintas dan pergerakan adalah dengan menghitung faktor pertumbuhan lalu lintas dan selanjutnya jumlah arus lalu lintas yang akan datang dapat dihitung dengan rumus sebagai berikut:

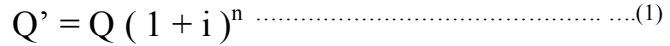

Dimana :

$\mathrm{Q}^{\prime}=$ Arus lalu lintas $\mathrm{n}$ tahun yang akan datang (smp/jam), $\mathrm{Q}=$ Arus lalu lintas saat ini (smp/jam), I = Faktor pertumbuhan lalu lintas $(\% /$ thn $)$, dan $\mathrm{n}=$ Jumlah tahun rencana (tahun).

Besarnya faktor pertumbuhan lalu lintas (i\%) diperoleh melalui analisis berdasarkan 
rata-rata pertumbuhan kepemilikan kendaraan lima tahun terakhir, pertumbuhan ekonomi lima tahun terakhir, pertumbuhan LHR, dan pertumbuhan lalu lintas jam puncak.

\section{Model Pemilihan Rute}

Model Pembebanan Lalu Lintas dengan Kurva Diversi. Untuk menghitung volume lalu lintas yang tertarik dengan adanya fasilitas rute jalan baru (Moskowitz, 1956). Besarnya pengalihan ditunjukkan dengan prosentase. Kemudian dari prosentase tersebut dikalikan dengan volume lalu lintas pada ruas-ruas jalan yang dipengaruhi oleh jalan tersebut. Pada Gambar 1 memperlihatkan hubungan antara penghematan jarak perjalanan menggunakan kendaraan bermotor (mil) dengan penghematan waktu perjalanan menggunakan kendaraan bermotor (menit).

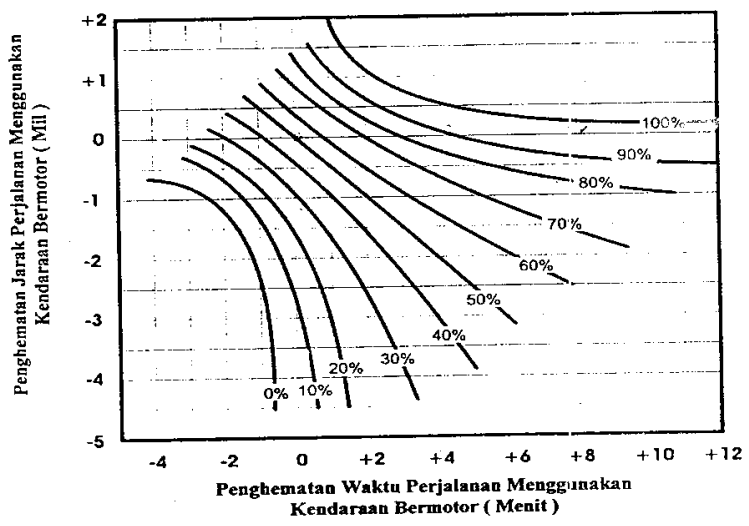

Gambar 1 Kurva Diversi

Sumber : Moskowitz (1956)

\section{Analisis Kinerja Ruas Jalan}

Analisis kinerja ruas jalan akibat perilaku arus lalu lintas yang ada atau yang diramalkan untuk tipe jalan perkotaan dapat dihitung dengan prosedur analisis sebagai berikut (Dep. PU,1997) :Kecepatan arus bebas, kapasitas, derajat kejenuhan, arus lalu lintas yang dapat dilewatkan oleh ruas/segmen jalan tertentu dengan mempertahankan tingkat kecepatan atau derajat kejenuhan tertentu dan kecepatan pada kondisi arus sesungguhnya.

\section{Kapasitas dan Tingkat Pelayanan Jalan}

Kapasitas suatu ruas jalan didefinisikan sebagai volume lalu lintas maksimum melalui suatu titik di jalan yang dapat dipertahankan persatuan waktu (Dep.PU, 1997). Ukuran kapasitas umumnya adalah kendaraan/jam atau smp/jam. Kapasitas jalan dihitung berdasarkan Manual Kapasitas Jalan Indonesia (Dep.PU, 1997) sebagai berikut :

$\mathrm{C}=\mathrm{Co} \times \mathrm{FC}_{\mathrm{W}} \times \mathrm{FC}_{\mathrm{SP}} \times \mathrm{FC}_{\mathrm{SF}} \times \mathrm{FC}_{\mathrm{CS}}$

Dimana :

$\mathrm{C}=$ Kapasitas (smp/jam)

Co $=$ Kapasitas dasar (smp/jam)

$\mathrm{FC}_{\mathrm{W}} \quad=$ Faktor penyesuaian lebar jalur

$\mathrm{FC}_{\mathrm{SP}}=$ Faktor penyesuaian pemisahan arah

$\mathrm{FC}_{\mathrm{CS}}=$ Faktor penyesuaian ukuran kota

Konsep tingkat pelayanan digunakan sebagai ukuran kualitas pelayanan jalan. Ukuran-ukuran yang cocok untuk menentukan tingkat pelayanan bisa diidentifikasi dari kecepatan atau volume kendaraan yang melewati suatu ruas jalan. Tingkat pelayanan jalan dikelompokkan atas enam kelompok, yaitu : tingkat pelayanan A, B, C, D, E dan F (Dep. PU, 1997).

\section{Derajat Kejenuhan}

Derajat Kejenuhan (Degree of Saturation/DS) didefinisikan sebagai rasio arus lalu lintas terhadap kapasitas jalan, digunakan sebagai faktor utama yang menentukan tingkat kinerja suatu segmen jalan (Dep.PU, 1997). Nilai derajat kejenuhan menunjukkan apakah segmen jalan akan mempunyai masalah kapasitas atau tidak. Derajat kejenuhan dinyatakan dalam smp/jam yang dapat dirumuskan sebagai berikut :

$$
\mathrm{DS}=\mathrm{Q} / \mathrm{C}
$$

Dimana ;

DS $=$ Derajat kejenuhan

$\mathrm{Q}=$ Arus lalu lintas total maksimum

$\mathrm{C} \quad=$ Kapasitas jalan $(\mathrm{smp} / \mathrm{jam})$

\section{Biaya Operasi Kendaraan (BOK)}

Secara teoritis biaya operasi kendaraan dipengaruhi oleh sejumlah faktor yaitu kondisi dan jenis kendaraan, lingkungan, kebiasaan pengemudi, kondisi jalan serta arus lalu lintas. Dalam prakteknya biaya tersebut diestimasi untuk jenis-jenis kendaraan yang mewakili golongannya dan dinyatakan dalam satuan moneter per satuan jarak $(\mathrm{Rp} / \mathrm{km})$. Berdasarkan model yang dikembangkan LPM- 
ITB (1997), biaya operasi kendaraan merupakan penjumlahan dari biaya gerak (running cost), dan biaya tetap (standing cost), yang secara rinci terdiri dari komponenkomponen sebagai berikut : Biaya gerak (Konsumsi bahan bakar, Konsumsi minyak pelumas, Perbaikan dan pemeliharaan kendaraan dan Penyusutan kendaraan) dan Biaya tetap (Bunga modal, Asuransi dan Overhead)

\section{Analisis Biaya Operasi Kendaraan (BOK) untuk Mobil}

Pada survey perbandingan pemakaian bahan bakar secara umum diperoleh bahwa rata-rata kecepatan pada jalan tol sebesar $50 \mathrm{~km} / \mathrm{jam}$ sementara pada jalan arteri antara 30-35 $\mathrm{km} / \mathrm{jam}$.

Pemakaiana bahan bakar untuk perhitungan BOK dihitung dengan menggunakan persamaan-persamaan berikut:

Untuk jalan Arteri,

a. Kend. Ringan : Y $=0,05693$ S2 $6,42593 \mathrm{~S}+269,18576$

b. Bus : $\mathrm{Y}=0,21692 \mathrm{~S} 2$ $24,15490 \mathrm{~S}+954,78624$

c. Truk : $\mathrm{Y}=0,21557 \mathrm{~S} 2-$ $24,17699 \mathrm{~S}+947,80862$

Untuk jalan Tol,
a. Kend.Ringan : $\mathrm{Y}=0,04376 \mathrm{~S} 2$ $4,94078 \mathrm{~S}+207,0484$
$16,10285 \mathrm{~S}+636,50343$
c. Truk
b. Bus
$: \mathrm{Y}=0,14461 \mathrm{~S} 2-$
$: \mathrm{Y}=0,13485 \mathrm{~S} 2-$
$15,12463 \mathrm{~S}+592,60931$

Dimana:

$\mathrm{Y}=$ Pemakaian bahan bakar (liter/1000 km)

$\mathrm{S}=$ Running Speed/Kecepatan berjalan (km/jam)

1. Pemakaian Minyak Pelumas

Pemakaian minyak pelumas/olie pada jalan arteri dan jalan tol dihitung dengan mengambil rasio pemakaian yang sama dengan untuk pemakaian bahan bakar. Persamaannya adalah sebagai berikut:

Untuk Jalan Arteri,
a. Kend. Ringan
$: \mathrm{Y}=0,00037 \mathrm{~S} 2-$
$0,04070 \mathrm{~S}+2,20403$
b. Bus : $\mathrm{Y}=0,00209 \mathrm{~S} 2-0,24413 \mathrm{~S}$
$+13,29445$
c. Truk
$0,22035 \mathrm{~S}+12,06436$
$: \mathrm{Y}=0,00186 \mathrm{~S} 2-$

\section{Penghematan Biaya Pemakai Jalan}

Nilai manfaat pembangunan jalan baru

bagi pengguna jalan adalah berupa penghematan biaya pemakai jalan yang terdiri dari penghematan biaya operasi kendaraan dan penghematan nilai waktu perjalanan. Besarnya penghematan kedua komponen tersebut dapat dihitung berdasarkan rumus dibawah ini :

$\mathrm{PB}=\left(\mathrm{BOK}_{\mathrm{ek}} \times \mathrm{D}_{\mathrm{ek}}-\mathrm{BOK}_{\mathrm{alt}} \times \mathrm{D}_{\mathrm{alt}}\right)+\left\{\left(\mathrm{D}_{\mathrm{ek}} / \mathrm{V}_{\mathrm{ek}}\right.\right.$

$$
\left.\left.-\mathrm{D}_{\text {alt }} / \mathrm{V}_{\text {alt }}\right) \times \mathrm{Tv}\right\}
$$

Dimana :

$\mathrm{PB} \quad=$ Penghematan biaya pengguna $(\mathrm{Rp})$

$\mathrm{BOK}_{\mathrm{ek}}=$ Biaya operasi kendaraan di jalan eksisting (Rp./km)

$\mathrm{BOK}_{\mathrm{alt}}=$ Biaya operasi kendaraan di jalan alternatif/tol (Rp./km)

$\mathrm{D}_{\mathrm{ek}} \quad=$ Panjang jalan eksisting $(\mathrm{km})$

$\mathrm{D}_{\text {alt }} \quad=$ Panjang jalan alternatif $(\mathrm{km})$

$\mathrm{V}_{\mathrm{ek}} \quad=$ Kec. di jalan eksisting $(\mathrm{km} / \mathrm{jam})$

$\mathrm{V}_{\text {alt }} \quad=$ Kec. di jalan alternatif/tol $(\mathrm{km} / \mathrm{jam})$

$\mathrm{Tv}=$ Nilai waktu kendaraan $(\mathrm{Rp} / \mathrm{jam})$

\section{Perhitungan Tarif Tol}

Berdasarkan Peraturan Pemerintah No 15 Tahun 2005 Tentang Jalan Tol, tarif tol dihitung sebagai berikut:

a. Tarip tol dihitung berdasarkan kemampuan membayar pengguna jalan tol, besar keuntungan biaya operasi kendaraan, dan kelayakan investasi.

b. Besar keuntungan biaya operasi kendaraan diatas dihitung berdasarkan pada selisih biaya operasi kendaraan dan nilai waktu pada jalan tol dengan jalan lintas alternatif jalan umum yang ada.

c. Evaluasi dan penyesuaian tarip tol dilakukan setiap 2 (dua) tahun sekali oleh BPJT berdasarkan tarip lama yang disesuaikan dengan pengruh inflasi sesuai dengan formula:

Tarif baru $=$ tarif lama $(1+$ inflasi $)$

Oleh LAPI-ITB (1997) , berdasarkan perhitungan komponen BOK dan Nilai Waktu secara formulasi ditulis : Tarif $<\left(\mathrm{BOK}_{\text {jalan lama }}\right.$ - BOK ${ }_{\text {tol }}$ ) dimana BOK diatas sudah termasuk nilai waktu. Penentuan besarnya tarif dibatasi maksimum sebesar 70\% PBPJ.

\section{Analisis Kelayakan Finansial}

Analisis kelayakan finansial proyek dilakukan berdasarkan penglihatan dari sudut 
pandang lembaga atau individu yang menanamkan modalnya dalam proyek atau yang berkepentingan langsung dalam proyek. Dalam analisis ini yang diperhatikan adalah hasil yang harus diterima oleh investor atau siapa saja yang berkepentingan dalam pembangunan proyek tersebut. Komponenkomponen manfaat dan biaya yang diperhitungkan adalah yang secara finansial berpengaruh langsung bagi kepentingan investor. Dengan demikian semua komponen biaya akan diperhitungkan, sedangkan komponen manfaat yang bersifat langsung saja yang diperhitungkan. Kriteria evaluasi dalam analisa finansial umumnya adalah Net Present Value (NPV), Benefit Cost Ratio (BCR), Internal Rate of Return (IRR), Payback Period dan Analisis Sensitifitas.

\section{Net Present Value (NPV)}

NPV didefinisikan sebagai selisih antara Present Value dari komponen manfaat dan Present Value komponen biaya. Secara matematis rumusnya adalah sebagai berikut:

$$
\begin{aligned}
& N P V=P V B-P V C . \\
& N P V=\sum_{t} \frac{B_{t}-C_{t}}{(1+i)}
\end{aligned}
$$

Dimana :

PV B = Present Value Benefit

PV C = Present Value Cost

$\mathrm{Bt}=$ besaran total dari komponen

manfaat proyek pada tahun $\mathrm{t}$

$\mathrm{Ct}=$ besaran total dari komponen biaya pada tahun $\mathrm{t}$

$$
\begin{array}{cl}
\mathrm{i} & =\text { tingkat suku bunga } \\
\mathrm{t} \% / \text { tahun }) & =\text { jumlah tahun }
\end{array}
$$

Berdasarkan kriteria ini dapat dikatakan bahwa proyek layak dikerjakan jika nilai NPV $>0$, sementara jika nilai $\mathrm{NPV}<0$ artinya proyek tidak layak dan jika nilai NPV $=0$ artinya tingkat pengembaliannya setara dengan suku bunga patokan (bank) atau dapat dikatakan bahwa proyek mengembalikan dananya persis sebesar Opportunity Cost of Capital (OCC), mengingat ada penggunaan lain yang lebih menguntungkan.

\section{Benefit Cost Ratio (BCR)}

Metode ini pada prinsipnya membandingkan semua pemasukan yang diterima (dihitung pada kondisi saat ini) dengan semua pengeluaran yang telah dilakukan (dihitung pada kondisi saat ini).

Secara matematis dapat dirumuskan sebagai berikut :

$$
\begin{aligned}
& B C R= P V B / P V C \\
& B C R=\frac{\sum_{t} \frac{B_{t}}{(1+i)^{t}}}{\sum_{t} \frac{C_{t}}{(1+i)^{t}}} .
\end{aligned}
$$

Dimana;

$\mathrm{Bt}=$ besaran total dari komponen manfaat proyek pada tahun $\mathrm{t}$

$\mathrm{Ct}=$ besaran total dari komponen biaya pada tahun $\mathrm{t}$

$\mathrm{i}$ = tingkat suku bunga (\%/tahun)

$\mathrm{t}=$ jumlah tahun

\section{Internal Rate of Return (IRR)}

Yang dimaksud dengan Internal Rate of Return adalah besaran yang menunjukkan harga discount rate pada saat NPV sama dengan nol. Internal Rate of Return sering disebut sebagai laju pengembalian modal. Kriteria untuk menetapkan kelayakan suatu proyek adalah bila IRR-nya lebih besar dari discount rate (tingkat suku bunga). IRR dapat dicari dengan cara coba-coba.

$$
\mathrm{IRR}=\mathrm{IR} 1-\mathrm{NPV} 1 \frac{\mathrm{IR} 2-\mathrm{IR} 1}{\mathrm{NPV} 2-\mathrm{NPV} 1}
$$

Dimana;

IRR = Internal Rate of Return

IR1 = Tingkat bunga penetapan ke-1

IR2 = Tingkat bunga penetapan ke-2

NPV1 $=$ Net Present Value dari hasil IR1

NPV2 = Net Present Value dari hasil IR2

\section{METODE PENELITIAN}

Lokasi yang dipilih dalam penelitian ini adalah rencana jalan Tol Bandara Ngurah Rai yang ada diwilayah Kabupaten Badung. Adapun yang menjadi pertimbangan pemilihan lokasi adalah pentingnya dibangun jalan alternatif sebagai suatu usaha mengatasi masalah transportasi pada ruas jalan Ngurah Rai - Nusa Dua. Data yang dibutuhkan dalam penelitian ini meliputi data primer dan data sekunder yang akan diperoleh secara langsung dilapangan, penelitian sebelumnya serta 
sumber-sumber informasi lainnya. Data Primer merupakan data yang diperoleh secara langsung di lapangan dengan cara survey seperti data volume lalu lintas dan data geometrik jalan. Data sekunder adalah data yang didapat dari berbagai sumber data dengan mengadakan pencatatan atau pengutipan dari sumber data yang sebelumnya telah diolah oleh instansi terkait, seperti; data asal tujuan perjalanan, Geometrik Jalan, statistik sosial ekonomi, dan data biaya pembangunan jalan tol.

Analisis data yang akan dilakukan meliputi analisis sebagai berikut:

1. Analisis manfaat pembangunan jalan tol bagi pengguna jalan

2. Analisis biaya pembangunan dan pemeliharaan jalan tol.

3. Analisis kelayakan finansial pembangunan jalan tol dari sisi investor.

Analisis manfaat pembangunan jalan tol adalah dengan menghitung manfaat berdasarkan penghematan biaya pemakai jalan. Penghematan biaya pemakai jalan ini adalah penghematan berdasarkan biaya operasi kendaraan dan nilai waktu. Biaya pembangunan jalan tol ini, terdiri

\section{HASIL DAN PEMBAHASAN}

\section{Kondisi Lalu Lintas Jalan Eksisting Tahun 2013}

Tabel 1 memperlihatkan nilai derajat kejenuhan $(\mathrm{Q} / \mathrm{C})$ dan waktu tempuh pada ruasruas jalan disekitar lokasi rencana proyek.

Tabel 1 Derajat Kejenuhan dan Waktu Tempuh

\begin{tabular}{|c|c|c|c|c|}
\hline No & Nama Ruas Jalan & $\begin{array}{c}\text { Panjang } \\
(\mathrm{km})\end{array}$ & $\mathrm{Q} / \mathrm{C}$ & $\begin{array}{c}\text { Waktu Tempuh } \\
\text { (menit) }\end{array}$ \\
\hline & Jalan By Pass Ngurah Rai & & & \\
\hline 1 & Simp. Sanur - Simp. Pesanggaran & 8.40 & 0.46 & 10.50 \\
\hline 2 & Simp. Pasanggaran - Simp. Kuta & 3.60 & 0.87 & 8.31 \\
\hline 3 & Simp. Kuta - Simp. Patung Ngr Ra & 3.80 & 1.07 & 3.58 \\
\hline 4 & Simp. Patung Ngr Rai - Simp. Unu & 4.30 & 1.06 & 6.50 \\
\hline 5 & Simp. Unud -Nusa Dua & 7.40 & 0.72 & 12.45 \\
\hline & Jalan Sekitarnya & & & \\
\hline 1 & Jalan Raya Tuban & 1.00 & 0.64 & 3.45 \\
\hline 2 & Jalan Uluwatu Jimbaran & 7.70 & 0.66 & 12.45 \\
\hline 3 & Jalan Pratama & 4.80 & 0.49 & 9.50 \\
\hline 4 & Ruas Pasar Bualu-Silitiga & 0.85 & 0.64 & 2.00 \\
\hline 5 & Jalan Uluwatu II Jimbaran & 1.50 & 0.78 & 2.00 \\
\hline
\end{tabular}

dari seluruh biaya modal, operasional dan biaya pemeliharaan jalan yang diperlukan, yang meliputi: Biaya untuk studi perencanaan, biaya untuk konstruksi jalan dan fasilitas jalan, biaya pengawasan konstruksi, biaya pemeliharaan berkala setiap 5 tahun dan biaya lainnya. Analisis kelayakan investasi pembangunan jalan adalah analisis finansial terhadap manfaat pembangunan jalan alternatif dan biaya yang diperlukan untuk pembangunan, pemeliharaan, serta operasional jalan tersebut hingga 30 tahun ke depan. Kriteria investasi yang digunakan seperti yang sering dilakukan dalam menganalisis kelayakan proyek adalah NPV, BCR, dan IRR. Selanjutnya juga dilakukan analisis sensitifitas kelayakan investasi dengan mengubah nilai suatu variabel dan mengamati pengaruhnya terhadap kelayakan investasi. Dengan demikian dapat diketahui sensitifitas pengaruh variabel tersebut terhadap kelayakan investasi. Pada studi ini, analisis sensitivitas dilakukan dengan mengasumsikan keadaan-keadaan terburuk yang mungkin terjadi seperti dibawah ini, yaitu : Biaya naik $20 \%$ manfaat tetap, Biaya tetap manfaat turun $20 \%$ dan Biaya naik $20 \%$ manfaat turun $20 \%$

\section{Kondisi Lalu Lintas Jalan Eksisting Dengan Adanya Jalan Tol}

Dengan dibukanya jalan Tol BenoaBandara-Nusa Dua diharapkan lalu-lintas yang membebani ruas-ruas jalan eksisting sebagian akan beralih ke jalan tol seperti diperlihatkan pada Tabel 2. Hal ini berarti volume lalu-lintas di jalan eksisting akan berkurang dan kinerja/tingkat pelayanan jalan eksisting dapat lebih baik.

Tabel 2 Tingkat Pelayanan Jalan

\begin{tabular}{|c|l|c|c|}
\hline No & Segment & \multirow{2}{*}{$\begin{array}{c}\text { Tingkat Pelayanan } \\
\text { Sebelum Adanya Tol }\end{array}$} & $\begin{array}{c}\text { Tingkat Pelayanan } \\
\text { Sesudah Adanya Tol }\end{array}$ \\
\hline A & Jalan Bypass Ngurah Rai & C & C \\
\hline 1 & Simp. Sanur - Simp. Pesanggaran & D & C \\
\hline 2 & Simp. Pesanggaran - Simp. Kuta & F & E \\
\cline { 1 - 2 } 3 & Simp. Kuta - Simp. Patung Ngurah Ra & F & E \\
\hline 4 & Simp. Patung Ngurah Rai - Simp. Unu & C & C \\
\cline { 1 - 2 } 5 & Simp. Unud - Nusa Dua & & \\
\hline & & & C \\
\hline B & Jalan Sekitarnya & C & C \\
\hline 1 & Jalan Raya Tuban & C & B \\
\hline 2 & Jalan Uluwatu Jimbaran & C & C \\
\hline 3 & Jalan Pratama & C & C \\
\hline 4 & Ruas Pasar Bualu-Siligita & D & \\
\hline 5 & Jalan Uluwatu II Jimbaran & & \\
\hline & & & \\
\hline
\end{tabular}




\section{Penghematan Biaya Pemakai Jalan dengan menggunakan TOL}

Penghematan biaya pemakai jalan (PBPJ) dihitung hasilnya ditampilkan pada Tabel 3 dan besaran komponen masing-masing ditunjukkan, sebagai berikut;

Tabel 3Harga Komponen-Komponen PBPJ

\begin{tabular}{clllrrr}
\hline No & \multicolumn{1}{c}{ Komponen PBPJ } & Notasi & Satuan & Kend.Ringan & \multicolumn{1}{c}{ Bus } & \multicolumn{1}{c}{ Truk } \\
\hline 1 & BOK jalan Eksisting & BOK $_{\text {ek }}$ & Rp/km & $1,639.00$ & $4,234.00$ & $3,871.00$ \\
2 & BOK jalan Tol & BOK $_{\text {tol }}$ & Rp/km & $1,261.00$ & $3,951.00$ & $3,558.00$ \\
3 & Panjang jalan Eksisting & $\mathrm{D}_{\mathrm{ek}}$ & $\mathrm{Km}$ & 25.80 & 25.80 & 25.80 \\
4 & Panjang jalan Tol & $\mathrm{D}_{\mathrm{tol}}$ & $\mathrm{Km}$ & 20.77 & 20.77 & 20.77 \\
5 & Kecepatan di jalan Eksisting & $\mathrm{V}_{\mathrm{ek}}$ & $\mathrm{Km} / \mathrm{jam}$ & 30.64 & 30.64 & 30.64 \\
6 & Kecepatan di jalan Tol & $\mathrm{V}_{\text {tol }}$ & $\mathrm{Km} / \mathrm{jam}$ & 80.00 & 80.00 & 80.00 \\
7 & Nilai waktu kendaraan & $\mathrm{T}_{\mathrm{v}}$ & Rp/jam & $6,075.25$ & $39,151.63$ & $4,205.95$ \\
\hline
\end{tabular}

Besarnya tarip tol didasarkan pada prinsip bahwa biaya pemakai jalan melalui jalan tol ditambah dengan tarif tol harus lebih rendah daripada biaya pemakai jalan apabila melalui jalan eksisting yang ada. Dengan kata lain tarip tol tidak melampaui penghematan biaya pemakai jalan. Dalam studi ini perhitungan tarif tol dibatasi maximum $70 \%$ dari penghematan biaya pemakai jalan. Terdapat 2 (dua) asumsi untuk menentukan besarnya tarif tol yang direncanakan yakni; $70 \%$ PBPJ dan 50\% PBPJ. Untuk tahun 2014 (saat mulai dibukanya jalan tol) tarip rencana untuk masing-masing asumsi adalah sbb;

\section{Analisis Finansial}

Kelayakan pembangunan jalan tol ini ditentukan berdasarkan nilai dari 3 (tiga) kriteria yaitu Net Present Value (NPV), Benefit Cost Ratio (BCR), dan Internal Rate of Return (IRR). Dalam studi ini analisis dilakukan dengan menggunakan tingkat suku bunga (pinjaman) sebesar $16 \%$. Dalam menentukan tarip tol dan anggaran biaya dihitung dengan asumsi inflasi rata-rata
- Untuk asumsi tarif tol sebesar 70\% PBPJ, besarnya tarip rencana untuk motor Rp 273,; kendaraan ringan Rp. 2.303,- ; bus Rp 7.365,- dan truk Rp 4.938,-.

- Untuk asumsi tarip tol sebesar 50\% PBPJ, besarnya tarip rencana untuk motor Rp 195,; kendaraan ringan $\mathrm{Rp} \mathrm{1.645,-} \mathrm{;} \mathrm{bus} \mathrm{Rp}$ 5.261,- dan truk Rp 3.527-

Sesuai dengan informasi dari PT Jasa Marga, tariff yang di berlakukan di jalan tol BenoaBandara-Nusa Dua untuk motor Rp 4.000,dan untuk kendaraan ringan Rp. 10.000,-.

nasional (berdasarkan data 5 (lima) tahun terakhir) sebesar 8,506 \%/tahun. Pertumbuhan kendaraan yang menggunakan jalan tol di prediksi dengan tingkat pertumbuhan tinggi sebesar 9.96\%/tahun. Dari analisis kelayakan finansial yang dilakukan berdasarkan kriteria analisis (NPV, BCR dan IRR) terhadap berbagai tahap dengan asumsi tarip yang telah ditetapkan oleh Jasa Marga hasilnya ditunjukkan pada Tabel 4.

Tabel 4 Hasil Analisis Kelayakan Finansial

\begin{tabular}{|c|c|c|c|c|}
\hline \multirow{2}{*}{ No } & \multirow{2}{*}{ Uraian } & \multicolumn{3}{|c|}{ Kriteria Analisis } \\
\hline & & NPV (Rp) & BCR & IRR (\%) \\
\hline 1 & Tahap 1 & $(1,586,137,984,347)$ & 0.4754 & 3.868 \\
\hline 2 & Tahap 2 & $25,722,943,153$ & 1.0080 & 18.563 \\
\hline
\end{tabular}




\section{SIMPULAN DAN SARAN}

\section{Simpulan}

Berdasarkan analisis dan pembahasan yang telah dilakukan dapat ditarik beberapa simpulan dalam studi kelayakan pembangunan jalan tol Benoa-Bandara-Nusa Dua sebagai berikut:

1. Kinerja jalan eksisting tanpa dan dengan adanya jalan Tol Benoa-Bandara-Nusa Dua adalah:

- Pada tahun 2011 beberapa ruas jalan eksisting kinerjanya telah mencapai tingkat pelayanan E seperti ruas jalan By Pass Ngurah Rai, dengan tingkat kejenuhan 0.93 Sementara volume lalu-lintas harian (LHR) untuk ruas diatas adalah 74.625 Smp/hari/2 arah.

- Berdasarkan pertumbuhan kendaraan dengan tingkat prediksi sedang i(4,99\%) kapasitas ruas jalan By Pass Ngurah Rai sudah dilampaui, mencapai tingkat pelayanan F (Tahun 2013).

- Dengan dibukanya jalan Tol BenoaBandara-Nusa Dua pada tahun 2013 kinerja ruas jalan eksisting pada umumnya menjadi lebih baik dengan tingkat pelayanan $\mathrm{E}$ dan tingkat kejenuhan 0.78 karena sebagian volume lalu-lintas beralih ke jalan tol.

2. Tarif tol yang didapat dari perhitungan adalah sebesar Rp 273,- untuk motor, Rp 2.303,- untuk kendaraan ringan, $\mathrm{Rp} 7.365$,untuk bus dan $\mathrm{Rp}$ 4.938,- untuk truck. Tetapi tariff yang diberlakukan adalah tariff yang telah ditetapkan oleh Jasa Marga yaitu Rp 4.000,- untuk motor, dan Rp 10.000,untuk Mobil dan kendaraan lainnya.

3. Secara umum proyek pembangunan jalan Tol Benoa-Bandara-Nusa Dua tidak layak secara finansial. Hal ini ditunjukkan oleh nilai NPV sebesar Rp-1.586.137.984.347, BCR sebesar 0,4754, dan nilai IRR seharga $3,8676 \%$, dengan asumsi suku bunga bank $16 \%$ dan pertumbuhan kendaraan (i) $9,96 \%$. Hal ini menunjukkan bahwa volume lalu-lintas yang diperkirakan melewati jalan tol dengan asumsi tingkat pertumbuhan kendaraan 9,96\% tidak memadai. Hasil analisis selanjutnya menunjukkan bahwa dengan asumsi pertumbuhan kendaraan sebesar $14,7 \%$ per tahun barulah menghasilkan nilai indikator yang layak secara finansial.

\section{Saran}

Berapa saran yang dapat diusulkan untuk lebih sempurnanya hasil penelitian ini adalah sebagai berikut:

1. Dalam menganalisis pertumbuhan lalulintas yang melewati jalan tol perlu dipertimbangkan pengaruhnya terhadap perubahan tata guna lahan yang dapat terjadi di wilayah-wilayah strategis (wilayah yang cukup dekat dengan daerah sekitar jalan tol).

2. Dalam studi ini tidak diperhitungkan kebutuhan penambahan lajur lalu lintas. Untuk itu dalam penelitian-penelitian selanjutnya disarankan untuk memperhitungkan kebutuhan penambahan lajur lalu-lintas tersebut.

\section{DAFTAR PUSTAKA}

Badan Pusat Statistik Propinsi Bali. 2010. Bali Dalam Angka 2009. Bali

Departemen Pekerjaan Umum. 1997. Manual Kupasitas Jalan Indonesia $(M K J I)$.Direktorat Jenderal Eina Marga, Jakarta

Husnan, S. dan Suwarsono, M. 2000. Studi Kelayakan Proyek, UPP AMP YKPN, Yogyakarta

Kodoatie, R J. 1995. Analisis Ekonomi Teknik, Penerbit Andi Offsef, Yogyakarta.

Morlok, E. K. 1988. Pengantar Teknik dan Perencanaan Transportasi (terjemahan), Penerbit Erlangga, Jakarta

Moskowitz, K. 1956. California Method of Assigning Diverted Traffic to Proposed Freeways. Higway Reaserch Board, Bulletin No. 130, California

Peraturan Pemerintah Replubik Indonesia, Nomor 15 Tahun 2005. Tentang Jalan Tol

Tamin, O.Z.2000. Perencanaan dan Pemodelan Transportasi, Penerbit ITB, Bandung

Tamin dan Nahdalina (1998). Studi Penentuan Tarif Tol Rencana Ruas Jalan GempolPasuruan-Rojoso oleh Tunggal Suro Budho H, Skripsi 2003, Malang

Undang-Undang Replubik Indonesia, Nomor 38 Tahun 2004, Tentang Jalan 